\title{
Building Information Modeling (BIM) for Facilities Management - Literature Review and Future Needs
}

\author{
Mehmet Yalcinkaya and Vishal Singh \\ Department of Civil and Structural Engineering, Aalto University, Finland \\ \{mehmet.yalcinkaya, vishal.singh\}@aalto.fi
}

\begin{abstract}
Facilities management (FM) is a discipline comprising of various operations, activities and maintenance services to support the main functions of an in-use building or facility. It demands comprehensive sets of information about the facility. While various FM information systems are currently being used to manage such information, the multifarious graphical and nongraphical information stored in Building Information Models (BIM) from the pre-use phase have not been sufficiently integrated in existing FM systems. BIM, with its visualization, interoperability and information exchange capabilities, can streamline FM activities. Hence, use of BIM for FM has gained global research interest. This paper analyzes this trend based on qualitative analysis of the state- of-art literature on the topic. In particular, this paper scrutinizes the nature of BIM and FM within their variety of functions and interactions. The analysis concentrates on the value-adding potential of BIM and reports the findings to designate the benefits of BIM for FM, and assess potential challenges that are hindering the effective use of BIM in FM.
\end{abstract}

Keywords: Building information modeling (BIM), facilities management (FM), asset management (AM).

\section{Introduction and Background}

The operation and maintenance phase of a construction project is the main trigger that increases the total life-cycle cost. Studies show that the total life-cycle cost of a project is five to seven times higher than the initial investment costs [1] and three times higher than the construction cost [2]. According to National Institute of Standards and Technology (NIST), the lack of interoperability among various model-based applications cost $\$ 15.8$ billion, of which, $\$ 10.6$ billion (two-thirds) of this cost is attributed to O\&M phase [3]. The majority of building information traditionally comes from paper based documents. The handover of information takes several weeks for collection of relevant and up-to-date information [5]. Another NIST report states that "an inordinate amount of time is spent locating and verifying specific facility and project information from previous activities. 
Much valuable data associated with the design, construction, and operation of a facility is lost during its life span" [9]. Therefore, information is the most emerging necessity for FM [4], since it requires tremendous amount of information for efficient O\&M of the facilities [5, 6, 7]. Further, facility managers encounter the issue of quality and timely-access to information for O\&M activities [8], and the need for more efficient methods to manage the information [5].

In BIM a digital representation of the building process can be used to facilitate the exchange and interoperability of information in digital format [10]. It is expected that the BIM data is captured and used across the entire project life-cycle. While BIM has been predominantly used in design and construction purposes for many years due to its visualization and coordination capabilities, there is an ascending interest in professionals to use BIM in FM activities. Whatever graphical and nongraphical data of the facility is collected in BIM during the project life-cycle can be used for various FM activities such as commissioning and close out, quality control, energy management, and maintenance and repair [11]. While there are other computer aided facilities management (CAFM) applications in which various data related with space management, assets, move management, O\&M is created, updated, and pushed for FM activities, the sources of information in these systems vary during the project life-cycle, leaving information handover processes inefficient [11]. BIM, in that case, has the potential to be a catalyst to improve efficiency by establishing the relationships between FM and other disciplines.

Although BIM is emerging and gaining acceptance in design and construction phases $[11,12]$, a recent survey of UK construction industry [13] suggests that only $39 \%$ of construction professionals are using BIM, only 54\% are aware of BIM, three quarters of people believe that industry is not clear enough about BIM, and only $27 \%$ of people trust BIM. Moreover, a recent global market research shows that $36 \%$ of the BIM-using contractors are currently in the low and medium level BIM engagement whilst $11 \%$ are at a very high BIM engagement level [14]. There are some pioneering organizations that push the usage of BIM for FM. However, people still have been unable to recognize and quantify the benefits of BIM for FM [13]. The requirements for successfully utilizing BIM for FM are not clearly understood [11] in terms of interactions and interrelations between BIM and FM. This paper reviews BIM and FM literature to understand their functions, interrelations and interactions. The review focuses on identifying the gaps, and assessing the value adding potential and potential challenges in using of BIM for FM.

\section{Data Collection and Research Methodology}

The source of research data is the collection of academic papers from various construction science, information technologies, and facilities management journals; technical reports from research institutes; book chapters; theses and dissertation studies; conference proceedings, and; white papers and newsletters from leading BIM software companies. These papers and articles were classified in terms of BIM, FM and BIM based FM (BIM\&FM) literature. Therefore the interactions of the papers from different backgrounds were identified during the qualitative 
analysis. A sample tabular representation of literature tracking is presented in Table.1. The findings reported in this paper are based on qualitative analysis. Keywords were assigned to the reviewed papers based on their focus and main contents. The analysis should highlight which BIM issues come more often for FM? What are the gaps? And, what are the key concepts and potential research areas?

Table 1. Sample tabular representation of literature tracking and review

\begin{tabular}{|c|c|l|c|c|c|}
\hline Number & $\begin{array}{c}\text { Document } \\
\text { Type }\end{array}$ & Keywords & BIM & FM & BIM\&FM \\
\hline 1 & $\begin{array}{c}\text { Journal } \\
\text { Paper }\end{array}$ & $\begin{array}{l}\text { Lifecycle, Benefits of BIM, } \\
\text { Building Design, etc. }\end{array}$ & & & $\bullet$ \\
\hline 2 & $\begin{array}{c}\text { Book } \\
\text { Chapter }\end{array}$ & $\begin{array}{l}\text { Early Integration, FM } \\
\text { Practices. etc. }\end{array}$ & & $\bullet$ & \\
\hline$\ldots$ & $\ldots$ & $\ldots$ & & & \\
\hline
\end{tabular}

The second step of the analysis is classification of the keywords with respect to the assigned paper's discipline (BIM, FM or BIM\&FM), Table 2. Therefore, the frequency of each assigned keywords is distributed for each discipline. This step of the analysis would show the associated subjects of papers and missing gaps of BIM implementation in FM.

Table 2. Distribution of keywords across different subjects

\begin{tabular}{|l|c|c|c|c|}
\hline Keywords/Frequency & Total & BIM & FM & BIM\&FM \\
\hline Information Exchange/Sharing & 23 & 3 & 2 & 18 \\
\hline Lifecycle & 14 & 2 & 2 & 10 \\
\hline$\ldots$ & $\ldots$ & $\ldots$ & $\ldots$ & $\ldots$ \\
\hline
\end{tabular}

\section{Results from the Analysis}

Initially 98 documents were reviewed under disciplines of BIM, FM and BIM\&FM. After the completion of review, the documents were re-evaluated and 11 of them were eliminated as they contributed very little to the topic. Thus the content analysis was performed on 87 papers. During the review, 57 keywords were identified and assigned to the papers.

Distribution of kevwords based on Table 1: Figure 1 shows the frequency of occurrence of keywords across all disciplines. As shown in Figure 1, information exchange/sharing, life-cycle, data integration/interoperability, maintenance practices, early integration to facility design and decision support are the most frequently discussed keywords in the reviewed literature. Most frequent keywords were determined by percentile assessment, and the keywords with less than 50 percentile were not considered for discussion in this paper. 


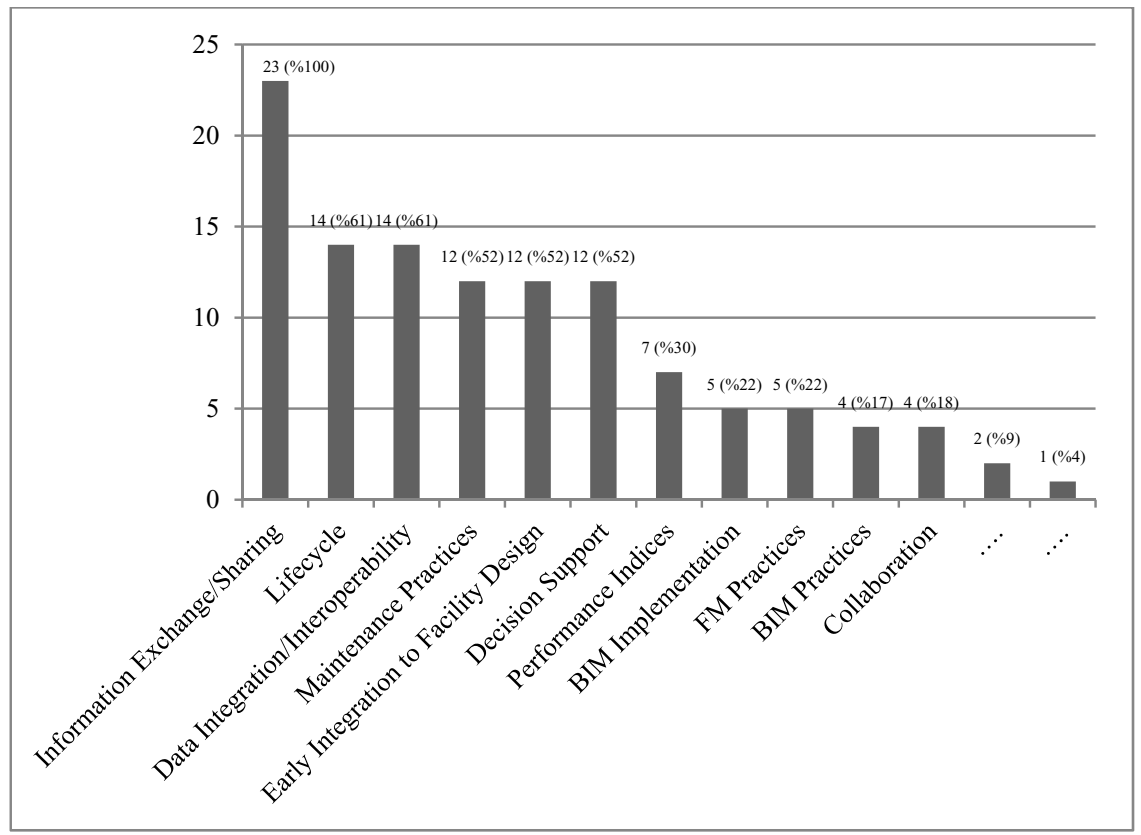

Fig. 1. Frequency of assigned keywords to the documents

Kevwords vs. Discipline based on Table 2: Based on the analysis using Table 2, the frequency of assigned keywords and interrelations between each discipline is presented in Figure 2.

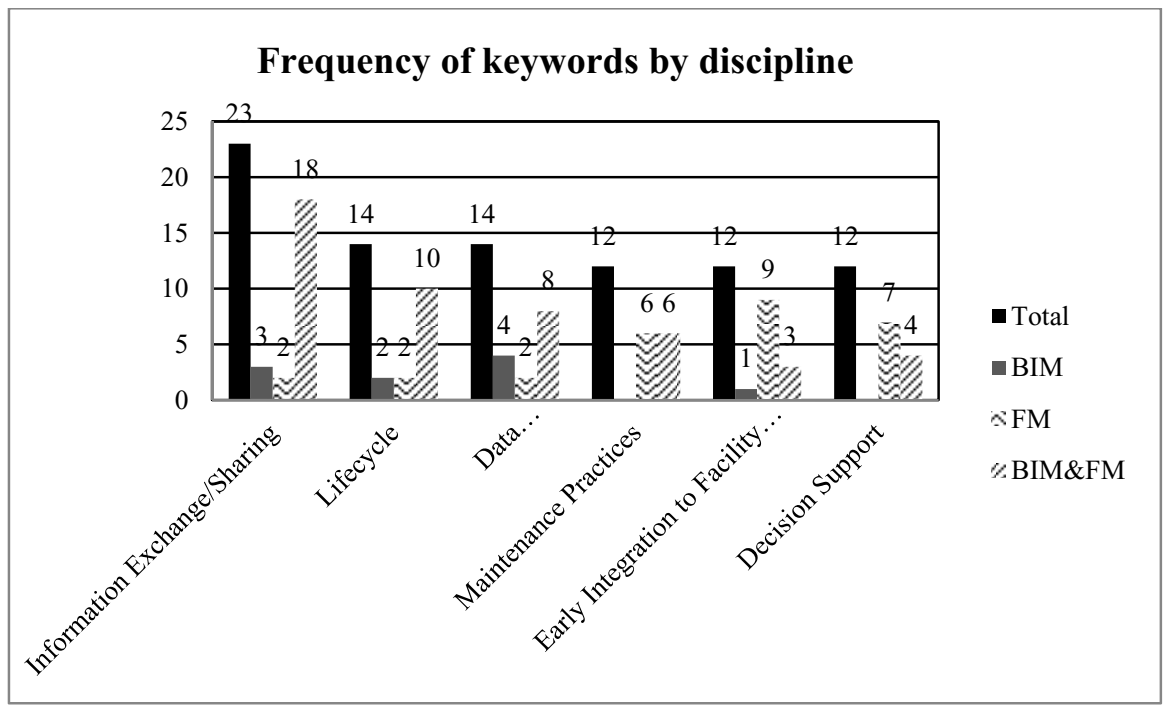

Fig. 2. Keywords and interrelations with each discipline 
Table 3 shows the overlap of keywords across these disciplines. The numbers shown in parentheses represent the frequency of the keywords. For example "Data Integration/Interoperability (4-2)" in row two, column three, indicates that the keyword "Data Integration/Interoperability" was assigned four times to BIM based papers, and two times to FM based paper.

Table 3. Interrelations of different disciplines for assigned keywords

\begin{tabular}{|c|c|c|c|}
\hline & BIM & FM & BIM \& FM \\
\hline BIM & & $\begin{array}{l}\text { Data Integration/Interoperability (4-2) } \\
\text { Decision Support (1-7) } \\
\text { Information Exchange/Sharing (3-2) } \\
\text { Life-Cycle (2-2) }\end{array}$ & $\begin{array}{l}\text { Data Integration/Interoperability (4-8) } \\
\text { Decision Support (1-4) } \\
\text { Information Exchange/Sharing (3-18) } \\
\text { Life-Cycle (2-10) }\end{array}$ \\
\hline & \multirow[t]{2}{*}{ FM } & & $\begin{array}{l}\text { Data Integration/Interoperability (2-8) } \\
\text { Decision Support (5-4) } \\
\text { Early Integration to Facility Design (9-3) } \\
\text { Information Exchange/Sharing (1-18) } \\
\text { Life-Cycle (2-10) } \\
\text { Maintenance Practices (6-6) }\end{array}$ \\
\hline & & BIM\&FM & \\
\hline
\end{tabular}

As shown in Table 3 when BIM and FM literature is compared, the keywords "data integration/interoperability" (4) in BIM; and "decision support" (7) in FM are the most frequent ones. When BIM and BIM\&FM literature is compared, the keywords "data integration/interoperability" (4) in BIM; and "information exchange/sharing" (18) in BIM\&FM are the most frequent ones. Finally when FM and BIM\&FM literature is compared, the keywords "early integration to facility design" (9) in FM; and "information exchange/sharing" (18) in BIM\&FM are the most frequent ones.

\section{$4 \quad$ Keywords and the Reported Issues}

\section{Information Exchange and Transfer: Interoperability and Decision Making}

BIM can be considered as a product, a process and a FM life-cycle management tool. Therefore, it is important for organizations to look at what they want out from BIM, and how. For an organization that implements FM functions and wants to use BIM in FM practices, it needs to consider several aspects connected to processes and usage of BIM prior to implementation. The findings of this review are directed towards identifying the basic minimum requirements to facilitate BIM for FM.

The data integration and information exchange for FM is mostly based on the integration of different IT tools. CAFM systems commonly use and integrate various building information. However, the re-usability of data in CAFM systems and the fragmented nature of construction industry make the information transfer challenging [18]. To overcome this problem, such systems which can integrate 3D BIM models and FM information in a database are being developed [18] as a knowledge-based BIM system [19] that enables better decision making. Since existing CAFM systems have inadequate capabilities and functions for collecting the 
building information pushed from various stakeholders and different phases of the project life-cycle, BIM based applications are being developed to simultaneously collect the data from different stakeholders and transfer this information to the facility manager in a cloud environment [20] to enable the mobility of facility manager during the FM activities. For such FM functions, BIM can act as a virtual database application. However, BIM is not enough by itself to collect and transfer the facility data simultaneously. To overcome this BIM systems need to integrate and communicate with technologies such as radio frequency identification (RFID). RFID provides wireless sensor technology to track and monitor the assets and building environment. The integration of RFID systems with BIM applications [21] through database servers and cloud services [22] provides access to the run-time data of the assets in a facility via either desktop or mobile devices.

A construction project involves different applications for various tasks such as architectural modeling, engineering analysis, and construction management. Despite technological advancements, the existing BIM systems or other IT based software applications are mostly implemented in isolation. There is also a lack of interoperability between systems. Therefore, sharing the data in such a heterogeneous environment becomes complicated. In addition, it is still not clear which facility data should be transferred by whom, when the related data should be transferred, and how [11]. To overcome this problem in terms of technology and strategy, several studies have been reported in the literature. A common interoperable computational environment such as extensible markup language (XML) has been proposed to facilitate the exchange, transfer, archival and re- usability of facility data through different database and software systems, and web-based environments [23]. However, XML may not be adequate for the all practices of construction industry which rely on several processes, people and products. The development of industry foundation classes (IFC) began in 1990s and it is still on going. IFC provides a framework for the digital representation of building design, engineering, construction, and operation data to facilitate information exchange between different BIM software. However, the information that is transferred with IFC contains lots of other information which are not needed for FM activities. Therefore, it should be filtered and modified for FM purposes. In response to this need to filter the information, the COBie (construction buildings information exchange) specification was developed to provide a structure for the lifecycle capture and delivery of facility information needed for FM purposes [24].

COBie is a simplified non-geometric subset of IFC [14] and can be created in IFC format or Excel [25]. COBie data includes rooms (spaces) and zones of the facility, equipment and its location, submittals, instructions, tests, certificates, maintenance, safety and emergency plans, start-up and shut-down procedure and resource data for the related activities [11]. Although there is an agreement about the requirement of $\mathrm{COBie}$ for structuring the facility data [26], COBie does not provide details on what information is to be provided, when, and by whom [27], and it has been found to be complex and unclear to use [28, 29]. At the same time, FMie (facility management information exchange) specifications are being developed by buildingSMART to link and exchange facility information more efficiently with the latest version of IFC [30].

Traditionally, the focus has been on the data that is created or updated during design and construction phases, but for effective FM practices, as-built data is needed. An accurate as-built model of the existing facility meets the owner's requirements and 
provides the best value [31]. The technology to produce as-built data (e.g. 3D laser scanning) needs to be integrated with other FM technologies and transferred through BIM process. Most existing technologies are not able to satisfy the integration and interoperability requirements between different systems.

\section{Early Integration to Facilities Design}

Successful implementation of FM functions depends on the identification of major requirements, functions and communications of the development at the earliest possible time [32]. Facilities design comprises the details of structural, architectural and MEP disciplines which elicit graphical and non-graphical information about the related facility. Considering the principle "begin with the final process in mind"; and FM needs and integration of owner/end-user and facility manager at the early design could potentially be worthwhile for the FM activities [33].

Another common subject mentioned in literature is the early integration of FM process to facilities design. Early engagement of FM could potentially reduce the needs for major repairs and alterations that will otherwise occur at the operational phase [34, 35 ] and will add value to the facility by establishing less rework and efficient control for supply chain. Facility managers have to identify the components' location and get access to the attributes and data relevant documents and maintenance information of the components. However, due to difficulty of altering the main structure and core service areas in the operational phase, it is hard to implement design process by considering operational conditions; and also most of the time designers do not care much about the factors in building maintenance [36]. Facility managers should also provide past maintenance information of facilities for the design team as a feedback. Since facility managers have a daily contact with users and obtain in-depth knowledge about the special needs for the facility, a knowledge transfer framework should be developed based on a combination of knowledge push from building operation, knowledge pull from building design [37]; and assumptions and specific facility requirements that are used as the input of design process [38]. The framework should also identify client's/end-user's organizational objectives while seeking to maximize the operational efficiency of the facility. The benefits of the integration of facility manager to facility design can decrease the cost of procurement due to reduction of rework in design and construction. Since the end-user/client requirements should be considered during the early phases, the facility can be better suited and more responsive to the needs, more attractive to potential users. BIM can be used as a potential tool. Implementation of BIM throughout design and construction stages, with the owners' and facility managers' data requirements in mind could provide an opportunity for facility managers [11]. However, one of the biggest challenges for BIM enabled FM practices is to define these data requirements, and to identify by whom and when the data should be provided through the project lifecycle. Although the data requirements are defined in the early phases, it is hard to follow these requirements due to dynamic and fragmented nature of a construction project. In addition to data requirements, interoperability and automated electronic data delivery are important for leveraging BIM in FM. Recent studies have attempted to clarify the information requirements and information transfer frameworks for facilities and asset management $[39,40]$. However, the companies should configure and adopt their existing management strategies with respect to these frameworks for the individual projects. Recent developments such as COBie [26] and FMie [30] facilitate and provide solutions 
to transfer up-to-date facility information from different phases of the project lifecycle. Apart from them, CAD technologies, building automation systems (BAS) and CAFM tools are other potential systems to collect and transfer the required FM information between maintenance and operation, and design phases [41]. Another challenge can be summarized with the cost issue. During the construction of a facility, the client/end-user looks for the most cost effective solutions. This situation may make the design considerations and actions which are evaluated by facility manager, less important. Therefore, facility managers may become less powerful than the decision makers during the facility design. This can be explained with the contradiction between commercial priorities of the client and the operational requirements of the facility [42].

\section{Conclusion}

BIM practices for planning, design and construction phases have been discussed and researched in the literature. Understanding the existing status of BIM for FM with the challenges and value-adding potential is fundamental at the early stage of a project. In this paper, the challenges and important aspects of BIM for FM are analyzed through a literature review. The findings from the review provide evidence that there is an agreement about the value and potential of BIM in FM. This research shows that the value of BIM in FM practices are mainly for:

- Automated data process and information transfer from the early stages of the project to the operation and maintenance phases,

- Increasing the efficiency of work orders and decision making process by access to real-time as well as previously stored graphical and non- graphical data.

However, there are several challenges that are hindering the effective use of BIM in FM. These include:

- The interoperability between BIM and different FM (CAFM, BAS, etc.) technologies

- The lack of clear requirements for the implementation of BIM in FM through early stages of the project

- Despite the documentation in [39] and [40], challenges exist in identifying clear roles, responsibilities and collaboration requirements of project team to provide and exchange the necessary information due to the traditional implementation practices and the adoption process

- Integration of as-built information with BIM and FM technologies

- Complexity and limitations of information exchange frameworks such as COBie that need to be clearer and more usable.

Among the other issues, due to the evolving nature of the BIM for FM field, and the different structures in the existing FM technologies, organizations should not fit their FM processes to suit a particular technology for decision making which would otherwise result in a continuous effort of adaptation. Instead, they should define the dynamics of their FM strategies and adapt the related specifications of BIM aspects, which suit their individual organizational and operational strategies. 


\section{References}

[1] Lee, S.-K., An, H.-K., Yu, J.-H.: An Extension of the Technology Acceptance Model for BIM-based FM. In: Construction Research Congress 2012 Construction Challenges in a Flat World, ASCE, pp. 602-611 (2012)

[2] BIM Task Group. The Government Soft Landings Policy (2012), http: / /www.bimtaskgroup.org/gsl-policy-2 (accessed January 12, 2014)

[3] N. GCR, Cost analysis of inadequate interoperability in the US capital facilities industry, National Institute of Standards and Technology (NIST) (2004)

[4] Atkin, B., Brooks, A.: Total facilities management (2009), http : / Wiley . com

[5] Teicholz, P.: BIM for Facility Managers (2013), http: / / Wiley .com

[6] Wang, Y., Wang, X., Wang, J., Yung, P., Jun, G.: Engagement of Facilities Management in Design Stage through BIM: Framework and a Case Study. Adv. in Civ. Engg. 13, 1-8 (2013)

[7] Janus, K.: The relationship between FM and IT. In: May, M., Williams, G. (eds.) The Facility Managers Guide to Information Technology, IFMA 2012, pp. 1-3 (2012)

[8] Sabol, L.: BIM Technology for FM. In: Teicholz, P. (ed.) BIM for Facility Managers, 1st edn., pp. 17-45. John Wiley \& Sons, New Jersey (2013)

[9] NIST, Cost analysis of inadequate interoperability in the U.S capital and facilities industry, http://fire.nist.gov/bfrlpubs/build04/art022.html (accessed December 23, 2013)

[10] Eastman, C., Teicholz, P., Sacks, R., Liston, K.: BIM handbook: A guide to building information modeling for owners, managers, designers, engineers and contractors (2011), http: / /Wiley.com

[11] Becerik-Gerber, B., Jazizadeh, F., Li, N., Calis, G.: Application areas and data requirements for BIM-enabled facilities management. Journal of Construction Engineering and Management 138(3), 431-442 (2011)

[12] Sabol, L.: Building Information Modelling and Facility Management, Design and Construction Strategies, http://dcstrategies.net/files/2_sabol_bim_ facility.pdf (accessed: September 21, 2013)

[13] NBS National BIM Report (2013), http://www. thenbs.com/pdfs/NBSNationlBIMReport2013-single.pdf (accessed: May 17, 2013)

[14] McGrawHill Smart Market Report (2013), http://bradleybim.files. wordpress.com/2014/01/2014_business_value_of_bim_for_constru ction_in_global_markets_smr_2014_.pdf (accessed January 25, 2014)

[15] Lane, T.: Tune in to BIM for FM (2013), http://www.building.co.uk/bim/ bim-in-practice/tune-in-to-bim-fm/5055672.article (accessed October 23, 2013)

[16] BIM-FM Workshop. Aalto University, Civil and Structural Engineering, BIM Research Initiative, Espoo-Finland (2013), https://wiki.aalto.fi/display/ABIM/ BIM+and+Facilities+Management (accessed January 12, 2014)

[17] Madritsch, T., May, M.: Successful IT implementation in facility management. Facilities 27(11/12), 429-444 (2009)

[18] Motawa, I., Almarshad, A.: A knowledge-based BIM system for building maintenance. Automation in Construction 29, 173-182 (2013)

[19] Wang, S., Xie, J.: Integrating Building Management System and facilities management on the Internet. Automation in Construction 11(6), 707-715 (2002)

[20] Jiao, Y., Wang, Y., Zhang, S., Li, Y., Yang, B., Yuan, L.: A cloud approach to unified lifecycle data management in architecture, engineering, construction and facilities management: Integrating BIMs and SNS. Advanced Engineering Informatics (2012)

[21] Shen, W., Hao, Q., Xue, Y.: A loosely coupled system integration approach for decision support in facility management and maintenance. Automation in Construction 25, 41-48 (2012) 
[22] Ko, C.-H.: RFID-based building maintenance system. Automation in Construction 18(3), 275-284 (2009)

[23] Teague, T., Palmer, M.E., Jackson, R.: XML for Capital Facilities. Leadership and Management in Engineering 3(2), 82-85 (2003)

[24] East, E.W., Nisbet, N.: Analysis of life-cycle information exchange. In: Tizani, W. (ed.) Proceedings of the International Conference on Computing in Civil and Building Engineering, vol. 30 (2010)

[25] Sabol, L.: BIM Technology for FM. In: Teicholz, P. (ed.) BIM for Facility Managers, 1st edn., pp. 17-45. John Wiley \& Sons, New Jersey (2013)

[26] Open BIM Network. "Open BIM focus" - COBie, issue 4 (October 2012)

[27] East, E.W., Carrasquillo-Mangual, M.: The COBie Guide: a commentary to the NBIMSUS COBie standard. Engineering Research Dev. Center, Champaign, IL, U.S (2013)

[28] Anderson, A., Marsters, A., Dossick, C., Neff, G.: Construction to Operations Exchange: Challenges of Implementing COBie and BIM in a Large Owner Organization. Construction Research Congress, 688-697 (2012)

[29] Gnanaredham, M., Jayasena, H.S.: Ability of BIM to satisfy CAFM information requirement. In: The Second World Construction Symposium 2013: Socio-Economic Sustainability in Construction (2013), http://suranga.net/publications / 2013_bim_cafm.pdf (accessed: June 9, 2014)

[30] Facility Management information exchange (FMie) (2012), http: / /www . nbef .no/ fileadmin/Styret/Styremoeter/Styremoete-2012-2/120302FMieProject-proposal_Rev_0_9_STS.pdf (accessed: January 5, 2014)

[31] Woo, J., Wilsmann, J., Kang, D.: Use of as-built building information modeling. Construction Research Congress 1, 538-547 (2010)

[32] Edum-Fotwe, F.T., Egbu, C., Gibb, A.: Designing facilities management needs into infrastructure projects: case from a major hospital. Journal of Performance of Constructed Facilities 17(1), 43-50 (2003)

[33] Kasprzak, C., Ramesh, A., Dubler, C.: Developing Standards to Assess the Quality of BIM Criteria for Facilities Management, AEI 2013@ sBuilding Solutions for Architectural Engineering, ASCE, pp. 680-690

[34] Jaunzens, D.: Adding value through facilities management, http: / / projects.bre. Co.uk/design/Download/management. PDF (accessed: January 18, 2014)

[35] Nutt, B., McLennan, P.: Facility management: risks and opportunities, Blackwell Sc. (2000)

[36] Arditi, D., Nawakorawit, M.: Designing buildings for maintenance: designers' perspective. Journal of Architectural Engineering 5(4), 107-116 (1999)

[37] Jensen, P.A.: Design interaction of facilities management: a challenge of knowledge transfer. Architectural Engineering and Design Management Journal 5, 124-135 (2009)

[38] Erdener, E.: Linking programming and design with facilities management. Journal of Performance of Constructed Facilities 17(1), 4-8 (2003)

[39] BIM Task Group, Employer's information requirements core content and guidance notes, http: / /www.bimtaskgroup.org/wp-content/uploads / 2013 / 04 /

Employers-Information-Requirements-Core-Content-andGuidance.pdf . (accessed June 03, 2014)

[40] British Standards Institute, Specification for information management for the operational phase of assets using building information modelling, http://shop.bsigroup. com/upload/Construction_downloads / PAS11923\%20 final\%20bookmarked.pdf (accessed June 03, 2014)

[41] Bröchner, J.: Integrated development of facilities design and services. Journal of Performance of Constructed Facilities 17(1), 19-23 (2003)

[42] Enoma, A.: The role of facilities management at the design stage, http: / / www . arcom.ac.uk/-docs/proceedings/ar2005-04210430_Enoma.pdf (accessed August 10, 2014) 